\title{
LÍMITES CONSTITUCIONALES DEL PRINCIPIO DE PRIMACÍA DEL DERECHO COMUNITARIO*
}

\author{
LEANDRO FERREYRA** \\ UniversidAd de Buenos Aires, Argentina \\ leanferreyra@hotmail.com \\ "And they say it's just a stage in life \\ But I know by now the problem is a stage \\ And they say just take your time and it'll go away \\ But I know by now I'm never gonna change" \\ Pete Townshend, Daily Records
}

RESUMEN: El presente trabajo aborda algunas cuestiones del derecho comunitario. En primer lugar, los rasgos básicos de dicho ordenamiento. Luego, se pasa a analizar el alcance de los mismos, especialmente del principio de primacía, y su relación con las disposiciones constitucionales de algunos Estados miembros de la Unión Europea. Asimismo, se estudian algunas resoluciones del tribunal comunitario y de tribunales constitucionales. Por último, se presentan algunas reflexiones sobre la necesidad de trascender los niveles de análisis meramente normativos para comprender mejor la falta de correspondencia entre la regulación comunitaria y la de cada Estado.

Palabras claves: Derecho comunitario, ordenamiento juridico, Estado, regulación.

\section{CONSTITUTIONAL LIMITS OF THE PRIORITY OF COMUNITARY LAW PRINCIPLE}

\begin{abstract}
The present essay adresses some issues about community law. First, the basic features of that legal system. Next, it analyzes the extent of them, particularly primacy principle, and its relation with constitutional provisions of some States members of the European Union. As well, it studies some resolutions by community court and constitutional courts. At last, it presents some considerations about the necessity to transcend purely normative analysis levels for a better understanding about the mismatch between community regulation and that of each State.
\end{abstract}

Keywords: Community law, legal system, State, regulation.

\footnotetext{
Trabajo recibido el 30 de agosto y aprobado el 8 de octubre de 2011.

** Estudiante de Abogacía, Facultad de Derecho.
} 


\section{INTRODUCCIÓN}

En el presente trabajo se analizarán los diseños constitucionales de algunos Estados miembros de uno de los principales esquemas de integración: la Unión Europea (en adelante, UE). Aquel análisis tiene a su vez otros objetivos. En primer lugar, plantear algunas cuestiones que surgen a partir de los principios del derecho comunitario consagrados a través de sentencias del Tribunal de Justicia de la Unión Europea, especialmente en lo concerniente a la primacía. Luego, divisar diferencias y similitudes entre las disposiciones de ciertas constituciones respecto de las posibilidades y modos de integración.

En segundo lugar, el trabajo tiene la aspiración de sacar conclusiones sobre la interacción de las normas constitucionales, las decisiones de algunos tribunales superiores y el sistema de integración de la UE. Principalmente, se planteará la necesidad de profundizar otros aspectos, como los culturales, para alcanzar soluciones más valiosas y proyectar la viabilidad del esquema comunitario a largo plazo.

\section{RASGOS BÁSICOS DEL DERECHO COMUNITARIO}

2.1. Como aproximación inicial, puede referirse al derecho comunitario como el conjunto de reglas de derecho aplicables al orden jurídico de la UE. Luego, el derecho comunitario es normalmente clasificado como originario o derivado. La primera categoría, derecho comunitario originario, está conformada por los tratados constitutivos ${ }^{1}$, que establecen objetivos, principios y la estructura institucional de la $\mathrm{UE}^{2}$. Por otro lado, el derecho derivado abarca un conjunto de actos jurídicos dictados por instituciones comunitarias en aplicación de los mentados tratados ${ }^{3}$.

El derecho derivado comunitario, también se puede clasificar según el alcance de cada tipo de fuente. Para los fines del presente trabajo basta diferenciar entre: a) reglamentos; b) directivas; c) decisiones.

Sin perjuicio de la enumeración de fuentes de derecho derivado, es necesario hacer referencia a algunas notas típicas del derecho comunitario ${ }^{4}$. Para ello hay que aclarar que si bien se

1 Entre los que se pueden mencionar: los tratados fundacionales de las Comunidades Europeas (Tratado de París de 1951, Tratados de Roma de 1957), los tratados de adhesión y los tratados complementarios y modificatorios (v.gr., Acta Única Europea de 1986, Tratado de la Unión Europea (TUE) de 1992, Tratado de Niza de 2001, Tratado de Lisboa de 2007).

2 Alejandro Iza agrega que "está integrado por normas convencionales. Las normas que lo constituyen se encuentran ubicadas en la cúspide de la pirámide jurídica comunitaria y son la norma suprema del derecho comunitario. Prevalece sobre el derecho derivado, del cual es su fundamento de validez, y también sobre todos los acuerdos que las Comunidades hayan firmado o puedan llegar a firmar con terceros Estados". Ver: IzA, Alejandro, Unión Europea ¿Paradigma de la integración?, Buenos Aires, Argentina: Departamento de Publicaciones, Facultad de Derecho, UBA, 2004, p. 155.

3 IzA, Alejandro, op. cit. (n.2), p. 155.

4 Dentro de la enumeración anterior, estas notas particulares se pueden vincular especialmente a los reglamentos (a), ya que en otros supuestos de derecho derivado pueden presentar distintos alcances. 
puede englobar al derecho comunitario dentro del derecho de la integración, el primero presenta ciertas particularidades. Tal como señala Luciana Scotti, esos aspectos peculiares son los que lo distinguen del resto del derecho de 1 itegración por estar ausentes en otros esquemas. Los mismos son de gran interés ya que, como se verá más adelante, matizan el análisis propuesto, al mismo tiempo que abren otros interrogantes. Esto se debe, en parte, a que no existe al día de hoy un reconocimiento expreso de esos principios característicos en los textos de los tratados constitutivos de la UE ni en las constituciones de los Estados miembros. A su vez, esto realza la importancia del Tribunal de Justicia de la Unión Europea (en adelante, TJUE), cuyo desarrollo jurisprudencial ha sido determinante para la evolución del derecho comunitario.

\subsection{Autonomía del Derecho COMUnitario}

El autor alemán Rainer Arnold indica que esta característica del derecho comunitario -la autonomía- encuentra su origen en la sentencia de los años sesenta Costa c. ENEL del Tribunal de Justicia de las Comunidades Europeas (en adelante, TJCE) ${ }^{6}$; asimismo, señala que la decisión fue receptada sin problemas por la jurisdicción de los Estados miembros ${ }^{7}$. Arnold también se encarga de enumerar algunas razones para afirmar la autonomía del ordenamiento en cuestión. En ese sentido, propone atender a tres condiciones básicas de la autonomía: 1) la procedencia de un ordenamiento propio, distinto del nacional, desde un sentido histórico; 2) la existencia de un mecanismo especial de creación de normas, condición en la cual no puede dejar de recordarse la supranacionalidad de los órganos con facultades legislativas ${ }^{8}$; 3) la razón de validez de ese ordenamiento supranacional y autónomo (la cual se funda, según el doctrinario alemán, en las leyes de aprobación que sanciona cada Estado; cuestión sobre la que se volverá más adelante) $)^{9}$.

Otro jurista europeo, Klaus Dieter-Borchardt, entiende que la autonomía del derecho comunitario es esencial para garantizar la validez uniforme del mismo en los Estados mibros Pero vale la pena citar otra vez a Arnold, quien aclara que "solamente si el Derecho comunitario constituye un ordenamiento autónomo puede plantearse un conflicto con el ordenamiento nacional”10.

Scotтi, Luciana, "La integración regional y el Derecho de la Integración - El caso del MERCOSUR: luces y sombras", en Suplemento Derecho Internacional Privado y de la Integración n ํ 18, p. 7. Buenos Aires, Argentina: Diario Jurídico El Dial, 2006.

6 El Tribunal de Justicia de las Comunidades Europeas (TJCE) cambió su denominación a partir de la entrada en vigor del Tratado de Lisboa, adoptando el nombre de Tribunal de Justicia de la Unión Europea.

7 Arnold, Rainer, “Conflictos entre ordenamientos y su solución”, en Revista de Derecho Constitucional Europeo (ReDCE), n ${ }^{\circ}$ 1, p. 99. Granada, Espańa, Enero-Junio de 2004.

8 Sobre este punto agrega que: "esta constatación alcanza también al derecho comunitario primario, que comparte con el derecho derivado su carácter autónomo y supranacional, porque el derecho primario es la base normativa (en el aspecto material e instrumental) de aquél". Ver: ArNold, Rainer, op. cit. (n.7), pp. 99-100.

9 Arnold, Rainer, op. cit. (n.7), p. 102.

10 ARnold, Rainer, op. cit. (n.7), p. 99. 


\subsection{Aplicabilidad inmediata}

Este rasgo implica, básicamente, la incorporación de las normas sin un acto de recepción, dependiendo su entrada en vigencia de las condiciones que el ordenamiento comunitario imponga ${ }^{11}$. En principio, las normas comunitarias están vigentes de acuerdo a lo que disponga la propia norma, siendo el único requisito su publicación en el Diario Oficial de la UE. A partir de esta característica, se ha pregonado doctrinariamente un sistema monista respecto del derecho comunitario.

\subsection{EFECTO DIRECTO}

Se ha precisado el efecto directo como la posibilidad de conferir derechos e imponer obligaciones de modo directo a instituciones comunitarias, Estados miembros e individuos ${ }^{12}$. Más allá de la distinción entre efecto directo horizontal y vertical ${ }^{13}$, el principio en cuestión queda nítidamente explicado en el caso Van Gend \& Loos del entonces TJCE. Si bien no se aclaraba qué tipos de disposiciones tenían efecto directo, el TJCE estableció en otro precedente (Francovich c. Italia) que incluso las directivas podían ser invocadas si eran suficientes, incondicionales y precisas.

\subsection{Primacía}

La relación entre el derecho comunitario y los ordenamientos jurídicos nacionales es (y ha sido) un tema muy discutido, ya que el Tratado de Roma no la ha regulado y tampoco las sucesivas reformas ${ }^{14}$. Pero sí se ha encargado de hacerlo el TJUE, a partir de sus decisiones sobre la primacía del derecho comunitario.

El reconocimiento del principio de primacía surge de la sentencia Costa c. ENEL del otrora TJCE. En esa resolución del año 1964 se dejaba sentado que: "la integración, en el Derecho de cada país miembro, de disposiciones que provienen de fuente comunitaria, y más generalmente los términos y el espíritu del Tratado, tienen por corolario la imposibilidad para los Estados de hacer prevalecer una medida unilateral posterior contra un ordenamiento jurídico aceptado por ellos sobre una base de reciprocidad"15.

\footnotetext{
Scotтi, Luciana, op. cit. (n.5), p. 7.

12 Dieter-Borchardt, Klaus, op. cit.(n.7), p. 97.

13 Correctamente detallada en: Sсотт, Luciana, op. cit. (n.5), p. 7.

14 Iza, Alejandro, op. cit. (n.2), p. 159.

15 Y se añadía que "una medida no puede ser inconsistente con aquel sistema legal. La fuerza ejecutiva del derecho comunitario no puede variar de Estado a Estado según la regulación local subsiguiente sin poner en riesgo los objetivos del Tratado". Ver: Costa c. ENEL, TJCE, Asunto 6/64, 15/07/1964.
} 
Seis años después de haber resuelto el caso Costa c. ENEL, el TJCE confirmó este principio respecto del derecho constitucional nacional ${ }^{16}$. De tal manera, la primacía supone que las normas comunitarias deberían aplicarse de manera preferente sobre las normas internas, con independencia del rango o condición anterior o posterior de las mismas ${ }^{17}$.

Si bien no ha habido mayores controversias sobre la primacía respecto del derecho interno infraconstitucional ${ }^{18}$, el alcance de la característica en lo relativo a la normativa constitucional no ha encontrado aún una delimitación definitiva en los ámbitos estatales.

Pocos años más tarde, apareció un interesante antecedente jurisprudencial, a nivel estatal, sobre la primacía del ordenamiento jurídico comunitario. Se trataba del caso conocido como Solange ${ }^{19}$, resuelto por el Tribunal Constitucional Federal Alemán (en adelante, TCFA) en 1974. Allí se pronunció sobre la relación entre el ordenamiento comunitario y nacional, basándose en la ausencia de un catálogo de derechos fundamentales a nivel comunitario. En ese caso se determinó que las posibilidades previstas en derecho comunitario eran insuficientes para garantizar una protección adecuada de los derechos básicos de los ciudadanos. Por lo tanto, el TCFA se rehusó a reconocer la primacía del derecho comunitario; además, declaró que, pese a no estar habilitado para decidir sobre la validez de actos de la Comunidad Europea, podría expedirse sobre la inaplicabilidad de normativa comunitaria si mediase una violación de derechos fundamentales ${ }^{20}$. Sin embargo, doce años más tarde, en Solange $I{ }^{21}$, el TCFA morigeró su postura, estableciendo que en tanto las Comunidades Europeas y las decisiones del TJCE aseguren una protección eficaz de derechos fundamentales, similar al resguardo constitucional, el Tribunal se abstendría de ejercer su jurisdicción para decidir sobre la aplicación de derecho comunitario secundario.

Así, se reconoció un ámbito de protección equiparable al que surgía de la Ley fundamental (lo cual luego fue recogido en el texto constitucional); y, mientras se mantuviese ese estándar, se renunciaría a controlar la compatibilidad de actos comunitarios con derechos fundamen-

16 En el caso Handelsgesellschaft, el TJCE decidió que: "[...] a la normativa del Tratado, una fuente de derecho independiente, no le puede ser opuesta, por su misma naturaleza, una disposición de derecho nacional sin que ello implique la privación del carácter comunitario y el cuestionamiento de la base legal comunitaria. Por lo tanto, la validez de una medida comunitaria o su efecto respecto de un Estado miembro no puede ser afectada por alegaciones conducentes a una supuesta contraposición a derechos fundamentales consagrados en la Constitución nacional o a principios de la estructura constitucional nacional". Ver: Internationale Handelsgesellschaft, TJCE, Asunto 11/70, 17/12/1970.

17 Teruel Lozano, Germán M. "El Tribunal Constitucional ante el principio de primacía en el derecho comunitario", en Anales de Derecho, n 26, Murcia, España: Universidad de Murcia, 2006, p. 328.

18 Josu de Miguel Bárcena opina que “[...] bien puede decirse que el ordenamiento comunitario funciona de manera correcta en ese nivel, respondiendo a los criterios tradicionales de unidad, coherencia y plenitud. Pero no ocurre lo mismo en el nivel constitucional". Ver: De Miguel Bárcena, Josu. "La justicia constitucional en la teoría de la Constitución Europea”, En: BazÁn, Víctor (Coordinador), Derecho Procesal Constitucional Americano y Europeo, Buenos Aires, Abeledo Perrot, 2010, p. 1539.

19 BVerfGE 37, 2712 BvL 52/71 Solange I-Beschluß, 29/05/1974.

20 Lindfelt, Mats. A bill of rights for the European Union?. Institute for Human Rights, Åbo Akademi University, 1999, p. 17.

21 BVerfGE 73, 3392 BvR 197/83 Solange II, 22/10/1986. 
tales constitucionalmente protegidos ${ }^{22}$. Asimismo, de Miguel Bárcena acota que la vigilancia sistémica, o doctrina de la sombra jurisdiccional, que abandera el TCFA se ha transformado en la doctrina dominante de la jurisprudencia de los principales tribunales superiores europeos ${ }^{23}$. Por su parte, Ortiz Vaamonde, desde una postura menos conflictivista, considera que, con resoluciones como la última del TCFA, la tensión entre el derecho comunitario y las constituciones nacionales se reduce, una vez alcanzado en el ámbito comunitario un nivel de protección de derechos fundamentales sustancialmente equivalente al garantizado por la Ley Fundamental ${ }^{24}$.

Por otro lado, resulta necesario mencionar que el frustrado Tratado Constitucional de la UE sí preveía expresamente el principio de primacía. En su art. I-6 se disponía que "la Constitución y el Derecho adoptado por las instituciones de la Unión en el ejercicio de las competencias que le son atribuidas primarán sobre el Derecho de los Estados miembros". Pese a la consagración expresa del principio emanado de los fallos del TJCE, el artículo no aportaba mucho a la cuestión de fondo ${ }^{25}$.

No obstante, el fracaso del Tratado Constitucional, se llevó consigo al art. I-6, ausente en el posterior Tratado Lisboa. Naturalmente, semejante omisión llamó la atención de quienes -erróneamente- habían visto un avance con tal artículo. Dentro de esa línea, Juan Manuel de Faramiñán Gilbert opina que, tras la reiterada jurisprudencia del TJCE, resulta un absurdo la supresión de la consagración en el Tratado Lisboa, lo cual sin dudas reflejaba un logro político y jurídico ${ }^{26}$. Empero, ese autor juzga que la disposición del Tratado Constitucional parece haberse transpuesto en la Declaración $n^{\circ} 17$ relativa a la primacía, anexa al Tratado de Lisboa, que prescribe: "con arreglo a una jurisprudencia reiterada del Tribunal de Justicia de la Unión Europea, los Tratados y el Derecho adoptado por la Unión sobre la base de los mismos priman sobre el Derecho de los Estados miembros, en las condiciones establecidas por la citada jurisprudencia”. A pesar de ello, tal declaración es, en principio, no vinculante; de modo que el Tratado de Lisboa no presenta ninguna novedad en lo concerniente a la relación entre los órdenes normativos referidos: los nacionales y el comunitario. Por lo tanto, sin perjuicio de lo dicho por Faramiñán

22 Ortiz Vaamonde. Santiago, "El Tribunal Constitucional ante el derecho comunitario", en: Revista Española de Derecho Constitucional, Año 21, n ${ }^{\circ}$ 61, Madrid, España, 2001, p. 342.

23 De Miguel Bárcena, Josu. op. cit. (n.19), p. 1543.

24 Y añade: "La tensión prácticamente se desvanece si se acepta que el derecho comunitario ha incorporado, como principios generales de los Estados miembros, los principios constitucionales esenciales que comparten, de modo que el Tribunal Comunitario ha de tener en cuenta la jurisprudencia de los Tribunales Constitucionales. En otras palabras, el problema del control de la adecuación de los actos comunitarios a los derechos fundamentales reconocidos por las Constituciones nacionales desaparece si se admite que el Tribunal de Luxemburgo puede llevarlo a cabo a la vista de la doctrina constitucional de los Estados miembros". Ver: Ortiz VaAmonde. Santiago,, op. cit. (n.23), p. 344.

25 Tal escepticismo se puede apreciar en la obra de Giuseppe de Vergottini, quien asevera que "el art. I-6 reitera el principio de primacía del derecho comunitario sobre el nacional, aunque se evita diligentemente afirmar la primacía sobre el derecho constitucional de los Estados". Ver: De Vergottini, Giuseppe. Garantía "de la identidad de los ordenamientos estatales y límites de la globalización”, en: Teoría y Realidad Constitucional, n ${ }^{\circ}$ 18, Madrid, España, UNED, 2006, p. 14.

26 De Faramiñan Gilbert, Juan Manuel. "El Tratado de Lisboa (un juego de espejos rotos)”, en: Revista Electrónica de Estudios Internacionales (REEI), no 19, 2007, p. 10. 
Gilbert y Ortiz Vaamonde, se encuentran más atinadas las ideas de Miguel Azpitarte Sánchez, quien explica que la cuestión sobre la primacía permanece aún indeterminada en algunos aspectos. En sus palabras, "las disfunciones estructurales e institucionales en la ordenación de las relaciones entre el ordenamiento de la unión y el ordenamiento estatal nacen por la irresoluta articulación entre el derecho constitucional estatal y el derecho de la unión. ¿Qué prima en la aplicación, el derecho originario de la Unión o las Constituciones estatales?"27.

Adoptando una posición coincidente con la de Azpitarte Sánchez, se debe afirmar que, más allá de lo resuelto por el TJCE, la cuestión está lejos de encontrar una solución clara y distinta. Si bien en los próximos puntos se avocarán a disposiciones constitucionales en términos generales, se intentará demostrar que en virtud de lo sucedido hasta el momento, especialmente con la situación irlandesa y la decisión reciente del Tribunal Constitucional alemán, no será posible hallar una salida sin tener en cuenta aspectos extra-jurídicos. Las simetrías que puedan encontrarse en distintos ámbitos -en los ordenamientos o resoluciones judiciales-, si las hubiese, y la indeterminación de los instrumentos del derecho comunitario respecto de la relación con los derechos internos, serán siempre remedios relativos hasta tanto no se aprehenda el contexto de la UE como un proceso de europeización constitucional y cultural ${ }^{28}$.

\section{DISPOSICIONES CONSTITUCIONALES RELATIVAS AL DERECHO COMUNITARIO}

3.1. Esta parte del trabajo se ocupará de presentar la normativa constitucional básica sobre el derecho comunitario y algunas resoluciones jurisprudenciales sobre aquella materia. Por cuestiones metodológicas, dado el gran número de Estados miembros, se acotará la presentación a un número reducido de constituciones. Sin embargo, la misma será suficiente a los fines propuestos anteriormente; es decir, para demostrar que las simetrías constitucionales generales, y las decisiones judiciales afines, no alcanzan para desentrañar la problemática de la primacía del derecho comunitario -como surge de la jurisprudencia del TJUE-, y la relación con el derecho nacional.

27 Igualmente, este autor aclara que "la Unión comparte valores constitucionales con los Estados miembros y antes ya resultaba chocante plantear una posible contradicción entre las normas primarias”. Ver: Azpitarte Sánchez, Miguel. "Las relaciones entre el derecho de la Unión y el derecho del Estado a la luz de la Constitución Europea”, en: Revista de Derecho Constitucional Europeo (ReDCE), no 1, Granada, España, 2004.

28 Para ello se parte del concepto amplio de constitución de Peter Häberle: "la Constitución no es sólo un orden jurídico para juristas y a interpretar por éstos según viejas y nuevas reglas artificiales; opera esencialmente también como guía para los profanos del Derecho: para todos los ciudadanos. La Constitución no es sólo un texto jurídico o una obra normativa reguladora, sino que también es expresión de una situación de desarrollo cultural, medio de autorrepresentación cultural del pueblo, reflejo de su herencia cultural y fundamento de sus esperanzas". Ver: Häberle, Peter. "El Estado Constitucional europeo”, en: Revista de Derecho Constitucional Europeo (ReDCE), n 11, Granada, España, 2009, p. 226. 


\subsection{Reino de los Países Bajos}

Como se podrá ver a continuación, esta es una de las normas fundamentales que recepta más abiertamente toda la normativa proveniente de tratados internacionales.

El art. 91.1 prevé que el Reino sólo puede quedar vinculado por tratados por aprobación previa del Parlamento. Además, el art. 93 fija que las estipulaciones de tratados y de acuerdos de organizaciones internacionales de derecho público que por su contenido puedan obligar a toda persona, tendrán fuerza obligatoria una vez publicadas.

Asimismo, el art. 94 contiene una de las regulaciones más particulares en torno la interacción entre derecho internacional e interno, en tanto posterga la aplicación del último -a nivel legal, no constitucional- si resulta contradictorio con el primero ${ }^{29}$. Y sobre la normativa constitucional, el art. 91.3 determina que "cuando un tratado contuviere estipulaciones que deroguen la Constitución o que impongan la necesidad de tal derogación, se requerirá para su adopción por las Cámaras una mayoría de al menos dos tercios del número de votos emitidos".

\subsection{EsPAÑA}

El art. 96 de la norma fundamental española prevé una regulación similar a la de los Países Bajos (art. 93), en lo concerniente a las condiciones de entrada en vigor de los tratados y el derecho derivado. Dejando las coincidencias, el art. 95 de la constitución española dicta que "la celebración de un Tratado internacional que contenga estipulaciones contrarias a la Constitución exigirá la previa revisión constitucional”. De ese modo, se aleja de la solución prevista en el art. 94 de la constitución holandesa, aunque dicha divergencia se basa en dos aspectos quizás no tan relevantes: 1) el procedimiento y la legitimación para solicitar la revisión (la constitución espańola permite al Gobierno requerir el análisis); 2) el poder encargado de realizar el test de conformidad constitucional (el legislativo en los Países Bajos, el judicial en Espańa).

Por su parte, el Tribunal Constitucional de España se ha manifestado hace unos años sobre la compatibilidad de la consagración expresa de primacía que incluía el Tratado Constitucional europeo.

El asunto $^{30}$ llegó al conocimiento del Tribunal ya que el Consejo de Estado entendía que la redacción del artículo I-6 del nuevo Tratado podía chocar con la consideración de la Constitución Española como norma suprema. Siguiendo lo sostenido en otra declaración (1/1992), el Tribunal aceptó expedirse, en tanto el art. 95 tiene como finalidad evitar la eventual perturbación que podría provocar una declaración de inconstitucionalidad. Así, se expidió detallando

29 El artículo en cuestión instituye que "los preceptos legales en vigor dentro del Reino no serán de aplicación, si la aplicación de los mismos fuere incompatible con estipulaciones de tratados y de acuerdos de organizaciones internacionales de derecho público que obligan a toda persona"

30 Tribunal Constitucional de Espańa, Declaración 1/2004, 13/12/2004. 
que "de este modo se confiere al art. $93 \mathrm{CE}$ una dimensión sustantiva o material que no cabe ignorar. Producida la integración debe destacarse que la Constitución no es ya el marco de validez de las normas comunitarias, sino el propio Tratado cuya celebración instrumenta la operación soberana de cesión del ejercicio de competencias derivadas de aquélla, si bien la Constitución exige que el Ordenamiento aceptado como consecuencia de la cesión sea compatible con sus principios y valores básicos". Es decir, que el Tribunal adoptó una postura análoga a la del TCFA en el caso Solange II; una solución híbrida y bastante equívoca. De hecho, se buscó mitigar (y eludir) la cuestión de fondo separando las nociones de primacía y supremacía, como categorías que se desenvolverían en órdenes diferentes. Así, determinó que la primacía no debe entenderse como superioridad jerárquica, sino como la capacidad de desplazar otras normas en virtud de una aplicación preferente en un ámbito concreto; o bien como una técnica del derecho comunitario destinado a asegurar su efectividad. Luego, halló a la supremacía constitucional "compatible con regímenes de aplicación que otorguen preferencia aplicativa a normas de otro Ordenamiento diferente del nacional siempre que la propia Constitución lo haya así dispuesto, que es lo que ocurre exactamente con la previsión contenida en su art. 93”. No obstante, aquella diferenciación no representa ningún avance en lo sustancial ${ }^{31}$.

\subsection{ITALIA}

La regulación de la constitución italiana sobre tratados internacionales es más bien escueta e indefinida. $\mathrm{El}$ art. 10, primera parte, prevé que "el ordenamiento jurídico italiano se ajustará a las normas del derecho internacional generalmente reconocidas". Luego, el art. 80 establece que "las Cámaras autorizaran mediante la ley la ratificación de los tratados internacionales[...]".

Respecto de las disposiciones constitucionales italianas, Alfonso Celotto indica que no se establecen pautas específicas para resolver eventuales contradicciones entre normas comunitarias y nacionales ${ }^{32}$. Acerca de la jurisprudencia italiana, de Miguel Bárcena cuenta que, asumiendo un criterio similar al del TCFA, la Corte Constituzionale "rechaza desde la década del setenta que las limitaciones a la soberanía reconocidas en el art. 11 puedan comportar para los órganos de la Unión un poder para violar los principios fundamentales del ordenamiento constitucional"33. Por su parte, Celotto señala que el parámetro elástico de los derechos fundamentales contribuyó a la formación de una teoría judicial de contralímites al derecho de la Unión que nunca tuvo aplicación práctica, figurando como una simple arma descargada ${ }^{34}$.

\footnotetext{
31 Josu de Miguel Bárcena afirma que "si la relación entre ordenamientos nacionales y el comunitario se observa desde el punto de vista de la supremacía constitucional, el resultado no es otro que el de una ruptura de la articulación del ordenamiento global en lo que concierne a la unidad”. Ver: De Miguel Bárcena, Josu. op. cit. (n.19), p. 1539.

32 Cецотto, Alfonso, "Normas comunitarias y derecho italiano", En: Derecho Procesal Constitucional Americano y Europeo, Buenos Aires, Argentina: Abeledo Perrot, 2010, p. 1562.

33 De Miguel Bárcena, Josu. op. cit. (n.19), p. 1543.

34 Cецотto, Alfonso, op. cit. (n.33), p. 1583.
} 


\subsection{Francia}

El título sexto de la constitución francesa contiene varias normas relacionadas con el tema del trabajo. En general, coinciden con lo dispuesto en las constituciones italiana y española. En cuanto a la incompatibilidad entre un tratado y la constitución, sólo caben comentarios similares a los mencionados en el punto 3.3.

La Constitución francesa incluye también un título específico -el $n^{\circ} \mathrm{XV}$ - sobre la UE. A pesar de la supuesta especificidad, tampoco se sugiere un aporte valioso a la materia examinada en este trabajo. En el inciso II del art. 88 se dispone que "de acuerdo con criterios de reciprocidad y del modo previsto por el Tratado de la UE, firmado el 7 de febrero de 1992, Francia concede las transferencias de competencias necesarias para el establecimiento de la unión económica y monetaria europea”.

En lo referente a la normativa comunitaria secundaria, el Consejo Constitucional concluyó que la transposición de una directiva puede ser obstaculizada por una disposición contraria de la Constitución nacional ${ }^{35}$. Si bien la decisión no delimita manifiestamente la relación entre los ordenamientos, la misma dio lugar a diversas interpretaciones. Por un lado, de Miguel Bárcena la enmarca correctamente dentro la línea del TCFA ${ }^{36}$. Mientras que Rodríguez Iglesias sostiene que, pese a no expedirse concretamente sobre las normas constitucionales, la decisión constituye un progreso hacia la aceptación del principio de primacía ${ }^{37}$. Justamente, en septiembre de $2004^{38}$, el Consejo Constitucional tuvo que expedirse sobre el mentado art. I-6 del Tratado Constitucional. En esta oportunidad, sumando a la consideración al art. I-5, sobre el respeto a la identidad nacional de los Estados miembros, puntualizó que el principio de primacía tendría como límite las estructuras fundamentales políticas y jurídicas ${ }^{39}$.

En $2007^{40}$, el Consejo decidió sobre la necesidad de una revisión constitucional previa a la aprobación del Tratado de Lisboa. La resolución se basó esencialmente en cuestiones de cesión de competencias, sin abordar la cuestión de la primacía, ya que no figuraba en el texto convencional en cuestión ${ }^{41}$. Pero el Consejo aprovechó la ocasión para confirmar la Constitución como norma suprema del ordenamiento jurídico interno.

35 Consejo Constitucional francés, Decisión 2004-496, 10/06/2004. rio para examinar la validez de una directiva”, en: Revista Derecho Comunitario Europeo, n ${ }^{\circ} 18$, Madrid, Espańa, 2004. Consejo Constitucional francés, Decisión 2004-505, 19/11/2004.

GAROT, Marie-José. "La Constitución francesa y el derecho comunitario: un repaso de la historia entre dos ordenamientos jurídicos", en: Revista Cuadernos de Derecho Público, Instituto Nacional de Derecho Público, Madrid, Espańa, 2008.

40 Consejo Constitucional francés, Decisión 2007-560, 20/12/2007.

41 Garot, Marie-José., op. cit. (n.40), p. 179. 


\subsection{Alemania}

La constitución alemana también contiene una disposición especial sobre la UE. El art. 23 establece que: "la República Federal de Alemania contribuirá al desarrollo de la UE que está obligada a la salvaguardia de los principios democrático, del Estado de Derecho, social y federativo y del principio de subsidiaridad y garantiza una protección de los derechos fundamentales comparable en lo esencial a la asegurada por la presente Ley Fundamental”. En términos generales, el contenido de la previsión constitucional guarda estrecha relación con lo resuelto en Solange II. Pero añade puntos críticos, como la subsidiariedad comunitaria y la nueva estructura del Estado alemán. A pesar de las valiosas especificaciones, la disposición referida tampoco impidió que se susciten divergencias en lo respectivo a la relación con el derecho comunitario ${ }^{42}$.

\subsection{IrLANDA}

La presencia de la normativa irlandesa no es baladí, sino que tiene un fin ulterior: probar que si el análisis del derecho de la integración se atiene a aspectos generales, deviene defectuoso.

La Constitución de Irlanda presenta dos puntos salientes en comparación al resto de las normas fundamentales mencionadas.

En primer lugar, cabe citar al artículo 29.4.10, el cual es el único entre las constituciones examinadas que confirma el alcance otorgado por el TJUE a la primacía del derecho comunitario ${ }^{43}$.

Sin embargo, la norma fundamental irlandesa también prevé una notable diferencia. Eso se debe a que en los artículos 27 y 29 se fija la necesidad de someter a referéndum la aprobación de determinados instrumentos. Entre ellos, el Tratado de Lisboa, el cual fue rechazado en 2008; aunque luego aprobado el 2 de octubre de 2009, con más del 60\% de votos afirmativos.

En principio, se podría concluir apresuradamente que la demora de la ratificación del Tratado de Lisboa se dio por este escollo procedimental irlandés. No obstante, tal reflexión sería desacertada en tanto no se inquiriesen las causas que propiciaron la negativa en primer lugar. Según explicó Ricardo Alonso García, en una disertación realizada en la Facultad de Derecho -UBA- ${ }^{44}$, el rechazo irlandés se debía en parte a las arraigadas tradiciones religiosas. Al parecer, la mayoría del pueblo irlandés habría motivado su objeción al nuevo tratado en el temor

42 Ver punto 4.2 .

43 Este artículo prescribe: "ninguna disposición de esta Constitución invalida las leyes sancionadas, los actos realizados o las medidas adoptadas por el Estado que sean necesarias por las obligaciones de la adhesión a la Unión Europea, ni previene que tengan fuerza de ley en el Estado las leyes, actos o medidas adoptados por la Unión Europea, por las Comunidades o las instituciones de la misma, o los cuerpos competentes según los Tratados constitutivos de las Comunidades".

44 La exposición intitulada Justicia Constitucional e integración europea tuvo lugar en el Instituto de Investigaciones Jurídicas y Sociales A.L. Gioja, Facultad de Derecho, UBA, el 4 de septiembre de 2009. 
al avance de la regulación comunitaria en algunos temas sensibles, como el aborto; avance que, a partir del art. 29.4.10, sería factible y problemático. De hecho, la Constitución de Irlanda es una de las pocas que consagra el derecho a la vida del nasciturus, con el debido resguardo por el mismo derecho respecto de la madre (art. 40.3.3).

A su vez, aquello no es una mera presunción infundamentada, sino que surge de los antecedentes que afirman preocupación irlandesa por el resguardo de ciertas cuestiones religiosamente polémicas. El caso, SPUC c. Grogan ${ }^{45}$, llegó a conocimiento del Tribunal comunitario luego de que la Suprema Corte irlandesa había manifestado que distribuir una guía con información relacionada al aborto constituía una violación al art. 40.3.3. El TJCE hizo algunas aclaraciones, pero no revirtió la decisión de la Suprema Corte, estableciendo que "no es contrario al derecho comunitario que un Estado miembro, en el que la terminación del embarazo no está permitida, prohíba a asociaciones estudiantiles la distribución de información sobre la identificación y locación de clínicas en otros Estados miembros en los que la terminación voluntaria del embarazo está legalmente permitida”.

A pesar de ese antecedente, Irlanda, el Estado formalmente más abierto la normativa comunitaria, casi consigue darle a la UE el mayor revés de su historia. Esto ayuda, pues, a entender las dificultades que debe atravesar todo proyecto de integración independientemente de las facilidades que se puedan proveer normativamente.

\subsection{Reino Unido}

Como es sabido, el Reino Unido de Gran Bretańa e Irlanda del Norte no tiene una constitución escrita. Si bien algunos precedentes judiciales ya habían determinado la jerarquía superior de algunas normas, en el caso Thoburn ${ }^{46}$, resuelto por la Queen's Bench Division, se instituyó una distinción entre leyes ordinarias y leyes 'constitucionales'; incluyéndose dentro de este último grupo la ley de Comunidades Europeas de 1972 ${ }^{47}$. Allí se decidió que: "una ley constitucional es aquella que (a) condiciona la relación legal entre los ciudadanos y el Estado de manera general, o (b) aumenta o disminuye el ámbito de lo que actualmente es reconocido como derechos constitucionales [...] La ley de Comunidades Europeas claramente pertenece a

45 The Society for the Protection of Unborn Children Ireland Ltd (SPUC) c. Stephen Grogan y otros, TJCE, Asunto 159/90, $04 / 10 / 1991$.

46 Thoburn v. Sunderland City Council, Queen's Bench Division, 22/02/2002.

47 Paul Craig comenta que "en la ley de Comunidades Europeas se regula a través del artículo 2 (1) que los derechos y obligaciones de la Comunidad serán reconocidos y ejecutados. No será necesario un nuevo acto de incorporación para permitir a los tribunales británicos que hagan cumplir la normativa comunitaria. El artículo 2 (4) estipula que cualquier regulación sancionada o por sancionarse deberá ser interpretada y tendrá efectos con sujeción a las disposiciones precedentes de este artículo". Ver: Craig, Paul. "The ECJ, National Courts and the Supremacy of Community Law”. En: Pernice, Ingolf y Miccù, Roberto (eds.), The European Constitution in the Making, Nomos, Baden-Baden, 2003, , p. 5. 
esta familia”. Además, en el parágrafo siguiente (el número 63), se aclaraba que las leyes 'constitucionales' estarían exentas de la derogación automática por una ley posterior (implied repeal), debiendo constar explícitamente la decisión de modificar la normativa anterior.

Tras la emisión de aquel pronunciamiento, se reavivó el debate británico sobre la soberanía parlamentaria ${ }^{48}$, ya afectada por lo decidido en los casos Factortame de los noventa. Pese a que ciertas cortes británicas siguen aclarando la vigencia de aquella doctrina ${ }^{49}$, es innegable que la normativa comunitaria ha adquirido un estatus legal especial en Reino Unido.

E independientemente de que se postule o no su primacía respecto del resto de la leyes británicas, lo más útil deviene de las álgidas manifestaciones en contra de la UE. Vale recordar que desde la incorporación a las Comunidades Europeas, el Reino Unido supo demostrar el mayor nivel de desconfianza respecto de las 'cesiones' de soberanía y recursos; por ejemplo, siendo el miembro principal en desechar la adopción del euro. Luego, con el paso del tiempo, aquel 'euroescepticismo' fue ganando adeptos paulatinamente, conquistando un lugar de privilegio en lo debates políticos, tal como se pudo ver en las campañas para las elecciones parlamentarias de 2010.

\section{REFLEXIONES Y CONCLUSIONES}

4.1. Siguiendo la línea expositiva y argumentativa de las dos partes anteriores, cabe concluir que en términos generales se advierte una similitud general entre las disposiciones de las constituciones referidas más arriba en lo que hace a la incorporación y relación ulterior del derecho interno -infraconstitucional- con el derecho internacional. No obstante, podría señalarse: 1) por un lado, la existencia de un gran conjunto de normas que coinciden en cuanto a requisitos y efectos; pero las coincidencias no pasan de un mero plano formal o procedimental (v.gr., modos de aprobación, publicidad); 2) por otro, la ausencia de disposiciones constitucionales referidas a la problemática central, salvo el art. 29.4.10 de la norma fundamental irlandesa; es decir que se puede detectar una indefinición relativa a los efectos sustantivos de las normativas constitucionales respecto de su relación con el derecho comunitario ${ }^{50}$.

48 La formulación tradicional de esta doctrina (parliamentary sovereignty) sostiene que solamente el Parlamento tiene la facultad de obligarse hacia el futuro. Ello en tanto tiene el derecho de sancionar o derogar leyes, y que ninguna otra persona o cuerpo está reconocido por el ordenamiento para tener el derecho de anular o dejar de lado la legislación parlamentaria. Ver: Craig, Paul, op.cit., p. 5; Eleftheriadis, Pavlos. "Parliamentary Sovereignty and the Constitution", en: Canadian Journal of Law and Jurisprudence, vol. XXII, nº 2, Ontario, Canadá, 2009.

49 Esta construcción deja intacto el núcleo esencial de la concepción tradicional de la soberanía legal, en el sentido que siempre queda latente la posibilidad de que el Parlamento deje inequívocamente claro que desea derogar el derecho comunitario. Ver: Craig, Paul., op. cit. (n.48), p. 7.

50 En las constituciones de los Países Bajos (art. 91.3), España (art. 95) y Francia (art. 54) se aclara la necesidad revisión de reglas contenidas en tratados que sean contrarias a disposiciones constitucionales. 
Pese a lo dispuesto en la constitución alemana sobre la UE, que no encuadraría en el punto 2) ${ }^{51}$ del párrafo anterior, el análisis propuesto lleva a mostrar cómo las simetrías constitucionales generales no alcanzan para esclarecer o determinar en términos expresos la relación entre los ordenamientos nacionales y el derecho comunitario. A su vez, tampoco son de mucha ayuda los pronunciamientos de los tribunales superiores estatales. Esto nos devuelve a la tesis de Azpitarte Sánchez sobre la falta de resolución de las articulaciones de los ordenamientos nacionales con el comunitario. Si bien esto no es ninguna novedad, al mismo tiempo no se debe dejar de hacer énfasis en esa indeterminación para paliar y prevenir controversias.

4.2. Con respecto a los efectos de esta zona de indeterminación del principio de primacía, es válido hacer referencia a una reciente sentencia del Tribunal Constitucional Federal Alemán (TCFA) del 30 de junio de 2009. En la misma, el TCFA resolvió que "con la Declaración n ${ }^{\circ} 17$ en cuanto a primacía, anexa al Tratado de Lisboa, la República Federal de Alemania no reconoce una primacía absoluta de la aplicación del Derecho de la Unión, lo que sería constitucionalmente objetable, sino que simplemente confirma la situación jurídica tal como ha sido interpretada por el Tribunal" 52 .

Ahora bien, ¿qué valor o sentido debe imputársele a la sentencia del TCFA y a otras similares reseñadas más arriba? La respuesta a la pregunta presenta dos aristas, que a su vez tienen un elemento en común: la necesidad de proponer un estudio más abarcativo del proceso de integración europeo.

4.3. La primera de las aristas referidas se encuentra relacionada con la ya mencionada opinión de Azpitarte Sánchez. No obstante, según se viene propugnando en este trabajo, el análisis no se debe detener en la falta de articulación expresa y determinada entre el derecho comunitario y los derechos internos. La citada sentencia del TCFA ejemplifica claramente que el problema sigue sin resolverse, y que pueda dar lugar a soluciones diversas; e incluso soluciones que no admitan la vigencia del principio de primacía en los términos de la jurisprudencia del TJUE. En ese sentido, la resolución confirmó "que la primacía de la aplicación del derecho de la Unión sólo se aplica en virtud, y en contexto, de la autorización constitucional, que sigue en vigor" ${ }^{3}$. Es decir, que más allá de las indeterminaciones constitucionales y de las sentencias del TJUE, el TCFA relativizó el alcance de la primacía del derecho comunitario. Además, dejó enmarcado al principio en un marco de incertidumbre aun mayor, soslayando el presunto avance logrado con el Tratado Constitucional y la declaración anexa al Tratado de Lisboa. Lo cual no sólo sienta más dudas, sino que permite elaborar una nueva concepción del principio. La reformulación mostraría, a su vez, que la primacía y otras notas típicas del derecho comunitario seguirán encontrando complicaciones para hallarse plenamente vigentes, en tanto se sujetan a la

51 Ya que se limita a seguir lo resuelto en el caso Solange II o la declaración 1/2004 del Tribunal Constitucional Español, y jurisprudencia similar de otros tribunales constitucionales, sin delimitar la relación concreta entre la primacía de uno u otro orden.

52 BVerfG, 2 BvE 2/08 vom 30.6.2009c, parágrafo 332.

53 BVerfG, 2 BvE 2/08 vom 30.6.2009c, parágrafo 240. 
voluntad política de cada Estado (al menos hasta ser expresamente consagradas en un tratado, y efectivamente acatadas). Tal posibilidad se deduce del siguiente razonamiento: 1) según sostiene Arnold ${ }^{54}$, solamente la existencia de un orden autónomo puede conllevar un conflicto entre dos ordenamientos, con un alcance sustantivo (alcanzando normas constitucionales); 2) sin embargo, hasta ahora la autonomía (y luego la primacía) del derecho comunitario encuentra su razón de validez en un acto interno de cada Estado ${ }^{55}$; 3 ) por lo tanto, ambos principios, autonomía y primacía dependen de la capacidad de cada Estado de autovincularse.

Por ello, si bien juzgo que la decisión del TCFA en el precedente citado en esta parte, fue acertada, es preciso remarcar que su motivación trasciende el encuadre normativo. Esa imposibilidad de concebir la primacía o la autonomía en términos absolutos deviene de razones que no son estrictamente jurídicas y que responden al interés de cada Estado. Aunque ya se hayan transitado etapas bastante complejas hacia la supranacionalidad, los Estados se siguen mostrando celosos al momento de cuidar o ceder parte de su soberanía.

4.4. Considerando lo indicado en los puntos anteriores, se puede ir delineando la siguiente conclusión: la insuficiencia de un fundamento estrictamente normativo para arribar a una decisión como la del TCFA. En ese sentido, lo ocurrido en Irlanda avala tal hipótesis. Pese a que no existen los elementos como para afirmar a ciencia cierta (si es que hay una ciencia 'cierta' no formal) cuáles fueron las causas del rechazo de 2008 al Tratado de Lisboa, la postura de Alonso García tiene elementos bastante sólidos. Tras una rápida lectura de la Constitución irlandesa, se advierte fácilmente que en la misma se ven consagrados ciertos valores de un modo peculiar (principalmente en cuanto a las creencias religiosas y la familia). Paralelamente, el puente que tiende la Constitución de Irlanda al derecho de la UE casi es derribado por otra disposición constitucional que le permitió al pueblo expresar su disconformidad con la adhesión al reformador Tratado de Lisboa.

Siguiendo esa línea de análisis, se debe empezar a tener en cuenta otro elemento del derecho comunitario: el factor social; que junto a los factores políticos, económicos y jurídicos (y no uno de ellos tomado aisladamente) conforman la noción pluridimensional del derecho comunitario $^{56}$.

4.5. A partir de lo expuesto, se ratifica la necesidad de robustecer otros niveles de análisis al quedar demostrada la precariedad de la legitimidad normativa del derecho comunitario. En lo concerniente a los análisis jurídicos, puede sostenerse que aquellos estudios se han vuelto cada vez más complejos, integrando factores sociales y culturales. Por lo tanto, se hace ineludible acompañar elementos que traspasen los límites normativos, para posibilitar la regulación de los diferentes contextos europeos en un ordenamiento comunitario común. Aunque se plantee

\footnotetext{
54 Ver nota 9 del presente trabajo.

55 Arnold, Rainer, op. cit. (n.7), p. 102.

56 Scotтi, Luciana, op.cit. (n.5), p. 3.
} 
como una tarea de difícil realización, para alcanzar una normativa más eficaz es vital perseguir una comprensión global de diferentes particularidades locales. Con ese objetivo, es imperante no sólo integrar las diversas cuestiones constitucionales en el derecho comunitario, sino también los elementos sociales y políticos subyacentes de cada ley fundamental o decisión de un tribunal, como el euroescepticismo británico o el catolicismo extremo de los irlandeses. De este modo, se enfrentan dos caminos.

Por un lado, en tanto cada Estado tiene una identidad específica -valor expresamente reconocido en varios tratados de la UE-, probablemente se podría variar el límite de algunos caracteres de la normativa comunitaria para garantizar su acatamiento. Quizá sea preferente establecer diversos alcances normativos según las necesidades de cada Estado y predicar las notas típicas del derecho comunitario solamente respecto a cuestiones fundamentales, que corroer la estabilidad del derecho comunitario en un vano intento de asimilar jurídicamente realidades absolutamente disímiles.

Por otro lado, también es cierto que, en el contexto actual de la UE, lo más conveniente sería evitar un retroceso en el valioso desarrollo que tuvo el derecho de la Unión. Así, se debería perseguir un cambio en ambos órdenes. Desde el espacio comunitario, reforzando el principio de subsidiaridad en cuanto al ejercicio de competencias ${ }^{57}$; lo cual traería aparejado una menor regulación comunitaria, aunque sobre cuestiones más sustanciales ${ }^{58}$. Desde el orden estatal, dejando las posturas tímidas y oscuras respecto de su relación con el derecho comunitario. La tensión constante entre la supuesta soberanía estatal -o la supremacía constitucional- y la primacía del derecho de la Unión no aporta nada al proyecto común europeo. Es más, la falta de resolución de estos temas asisten a la desaceleración de la integración en otros niveles. Si los Estados optasen por sincerarse, y se abandonasen las posturas vagas de los tribunales constitucionales ${ }^{59}$, se abriría el campo general de la normativa comunitaria y se precisarían sus contornos. Por eso, en el nuevo contexto europeo debe darse un proceso de complementación de políticas estatales y comunitarias que, advirtiendo los aspectos sociales y culturales actuales, reformule el ámbit

57 El art. 1 apartado 6 del Tratado de Lisboa, que recoge el texto del TUE, prescribe: "en virtud del principio de subsidiariedad, en los ámbitos que no sean de su competencia exclusiva, la Unión intervendrá sólo en caso de que, y en la medida en que, los objetivos de la acción pretendida no puedan ser alcanzados de manera suficiente por los Estados miembros, ni a nivel central ni a nivel regional y local, sino que puedan alcanzarse mejor, debido a la dimensión o a los efectos de la acción pretendida, a escala de la Unión”.

58 De hecho, en la decisión sobre el Tratado de Lisboa (ver nota 41), el Consejo Constitucional francés sentó sus dudas sobre el alcance otorgado al principio de subsidiariedad, estableciendo que "que, sin embargo, la aplicación de este principio podría no ser suficiente para impedir que las transferencias de competencia autorizadas por el Tratado revistan una amplitud o intervengan según modalidades tales que puedan verse afectadas las condiciones esenciales de ejercicio de la soberanía nacional".

59 Josu de Miguel Bárcena postula "que el TJCE y los tribunales constitucionales nacionales no están de acuerdo en los casos de zona de penumbra en la apreciación de la regla de la primacía, lo que conlleva una visión distinta de la relaciones entro ordenamientos. [...] La cooperación y el diálogo jurisprudencial en forma de prevención permanente por parte de los tribunales constitucionales nacionales sólo tiene sentido si se llega hasta el final de los argumentos jurídicos y se incorpora a la tradición constitucional común europea que tanto se predica la Constitución material de cada Estado miembro". Ver: de De Miguel BÁrCEnA, Josu. op. cit. (n.19), p 1560. 
del derecho comunitario. En esta línea, Konrad Hesse considera que "la futura Unión Europea sólo podrá cumplir eficazmente sus tareas si su ejecución es descentralizada y observa el principio de subsidiariedad; esto es, si se limita a cuanto requiera una regulación uniforme" 60 . Aunque también señala que "cuanto más conecte el derecho constitucional con tales circunstancias -el cambio en la realidad histórica-, cuanto mejor asuma las fuerzas y tendencias de cada época, mejor podrá desplegar sus efectos"61.

En ese orden de ideas, es preciso citar la concepción de Peter Häberle respecto de la europeización del Estado constitucional europeo. Este jurista propone no sólo sumar la cultura a los tres elementos tradicionales del Estado (pueblo, poder y territorio), sino que opina que la cultura debe ser el que los 'llene'. Por ello, ese Estado Constitucional será el resultado de la interacción de las diferentes identidades de los pueblos europeos, resaltándose así una de las notas peculiares de la integración en Europa: la pluralidad ${ }^{62}$. Coincidentemente, Rainer Arnold expresa que es de suma necesidad asegurar un plano de equilibrio entre la supranacionalidad de la UE y la garantía de preservación de la identidad nacional de los Estados miembros ${ }^{63}$.

Indudablemente, estas nuevas bases de estudio proveerán mejores soluciones a problemas como la falta de articulación entre la normativa de la UE y la de sus Estados miembros, y además harán que las conclusiones que se puedan obtener respecto de la viabilidad del esquema comunitario -en todos sus aspectos- sean más valiosas y precisas. En la actualidad, tales estudios y proyecciones se hacen cada vez más necesarios, ya que la crisis bursátil mundial desatada a fines de 2008 y sus ramificaciones han herido severamente la solidez comunitaria y estadual. Si bien hasta ahora las consecuencias negativas se advierten principalmente a nivel económico, con los problemas de Grecia ${ }^{64}$ se están empezando a vislumbrar serias dificultades en el horizonte comunitario. A su vez, los griegos no están solos en la crisis, sino que España, Irlanda y Portugal asimismo se hallan en situaciones muy delicadas, con tasas de desempleo superiores al 20\% y aumentos constantes de déficit y deudas del sector público; y con relaciones porcentuales alar-

60 Y ańade: "de todas formas, es innegable un profundo cambio: la evolución del Estado desde su concepción tradicional como soberano, nacional, relativamente, hermético, hacia el Estado actual internacionalmente imbricado y supranacionalmente vinculado, se corresponde con la pérdida de primacía y de la entidad e importancia que hasta muy recientemente había tenido su Constitución”. Ver: Hesse, Konrad. "Constitución y Derecho Constitucional” En: Manual de Derecho Constitucional, Instituto Vasco de Administración Pública, Madrid, España, Marcial Pons, 1996, , p. 14.

61 Hesse, Konrad, op. cit. (n.61), p. 8.

62 Häвerle, Peter, “El Estado Constitucional europeo”, en: Revista de Derecho Constitucional Europeo (ReDCE), n ${ }^{\circ} 11$, p. 423. Granada, España, 2009.

63 ARnold, Rainer, El Tratado de reforma de Lisboa: algunas reflexiones desde la perspectiva alemana, ReDCE, $\mathrm{n}{ }^{\circ}$ 9, Granada, Espańa, p. 243.

64 En abril de 2010 varios países de la UE aprobaron, junto al FMI, un plan de ayuda económica-financiera para el Estado griego, subsumido en un presente de altísimo déficit público y de decrecimiento sostenido de la economía, por más de 100.000 millones de euros. Pero tal plan tiene implica una serie de cambios de difícil realización a corto plazo (reducción de 30.000 mil millones de euros de gasto público a tres años). De hecho, ahora, en mayo de 2011, los griegos ya están solicitando un adelantamiento de las cuotas del 'rescate' para poder afrontar sus obligaciones económicas. 
mantes respecto del PBI. En estos últimos países, y también en Francia, Italia, el Reino Unido y otros miembros de la UE, ya se han anunciado varios planes basados en drásticos recortes fiscales y aumentos impositivos ${ }^{65}$.

Pero los inconvenientes no sólo atraviesan fronteras, afectando a los Estados vecinos, sino que alcanzan a la estructura misma de la UE. En primer lugar, de un modo directo, con la protección del euro ${ }^{66}$, la cual alteró bruscamente las arcas de organización. En segundo lugar, y ya volviendo a aspectos más ligados al tema central del presente trabajo, con las dudas del resto de los Estados miembros sobre hasta qué punto deben ayudar a otras economías estatales que sufren los resultados de administraciones aun más ineficaces. A su vez, estas dudas surgen desde dos frentes: 1) por un lado, desde la sociedad, que ve como una posibilidad cierta e injusta que se destinen recursos propios, cada vez más comprometidos, a otros países; 2) por otro, desde los sectores dirigenciales, ya que los gobernantes no quieren cargar con el costo político de asumir deudas extranjeras cuando apenas pueden lidiar con las propias. Cabe señalar que los últimos dos casos ya no son meras dudas o hipótesis, sino que se han manifestado en Alemania ${ }^{67}$ y el Reino Unido a lo largo de 2010.

4.6. Por último, considero pertinente retomar cuestiones tratadas a lo largo del trabajo para abordar algunos cambios concretos en los ámbitos normativos y administrativos europeos. Así, se debe distinguir entre los cambios producidos en el proceso de europeización -referido por Häberle- a nivel constitucional, y aquellos a nivel legal o reglamentario, sobre los cuales sí se puede afirmar la plena eficacia de los principios de derecho comunitario. Con el surgimiento de la UE, una entidad supraestatal, se ha vuelto innegable la variación de la relación entre el derecho interno de cada país (de nivel infraconstitucional) y el derecho comunitario. Más precisamente, se podría afirmar que se está enfrentando una crisis de las construcciones normativas tradicionales a partir de la evolución de nuevos ámbitos de producción y aplicación en instituciones comunitarias. Semejantes cambios no sólo afectan el binomio derecho interno-derecho comunitario, y las cuestiones de primacía de uno u otro orden, sino que se extienden alterando las estructuras normativas y administrativas de cada Estado y de la UE.

Lo importante, entonces, será rescatar elementos que permitan realizar un estudio y un seguimiento particularizado de ese desarrollo de la europeización, para poder moldear cuanto sea posible y de la manera más óptima las bases de esas redefiniciones jurídicas y administrativas.

65 Todos estos Estados han fijado aumentos del IVA en un promedio de dos puntos porcentuales y han dispuesto la abolición de exenciones fiscales. Al mismo tiempo, las reducciones del gasto público van desde los 7200 millones de euros en el Reino Unido, a 10.000 en Alemania, 15.500 en Espańa y 24.000 en Italia.

66 El 10 de mayo de 2010 se oficializó la aprobación de un fondo de emergencia (también acordado por Estados miembros y por el FMI) para el blindaje del euro y la solvencia de las deudas públicas nacionales, por montos superiores a los $750.000 \mathrm{mil} \mathrm{mi-}$ llones de euros.

67 Precisamente con la derrota de la coalición gubernamental de demócratas cristianos y liberales (de la cual forma parte la canciller, Angela Merkel) en las elecciones regionales que tuvieron lugar el 9 de mayo de 2010 en el land más próspero de Alemania (Renania del Norte-Westfalia). 
En conclusión, los referidos cambios suponen no sólo la necesidad de estudios más dilatados de materias estatales y comunitarias (y consiguientemente de derecho interno y de derecho comunitario), sino también la crisis definitiva de un modelo de aprehensión de cuestiones jurídicas y políticas demasiado ceñido. A su vez, todo ello implica el paso a un nuevo paradigma, en el cual las distintas esferas aparecerán, al mismo tiempo, más difusas e interdependientes.

\section{REFERENCIAS BIBLIOGRÁFICAS}

Arnold, Rainer. "Conflictos entre ordenamientos y su solución”, en: Revista de Derecho Constitucional Europeo (ReDCE), no 1, Granada, 2004.

"El Tratado de reforma de Lisboa: algunas reflexiones desde la perspectiva alemana”, en: Revista de Derecho Constitucional Europeo (ReDCE), N99, Granada, España, 2008.

Azpitarte Sánchez, Miguel. "Las relaciones entre el derecho de la Unión y el derecho del Estado a la luz de la Constitución Europea”, en: Revista de Derecho Constitucional Europeo (ReDCE), no 1, Granada, España, 2004.

Celotto, Alfonso. "Normas comunitarias y derecho italiano”, En:_Bazán, Víctor (Coordinador), Derecho Procesal Constitucional Americano y Europeo, Buenos Aires, Argentina:, Abeledo Perrot, 2010.

Craig, Paul. "The ECJ, National Courts and the Supremacy of Community Law”. En: Pernice, Ingolf y Miccù, Roberto (eds.), The European Constitution in the Making, Nomos, Baden-Baden, 2003.

De Faramiñan Gilbert, Juan Manuel. "El Tratado de Lisboa (un juego de espejos rotos)”, en: Revista Electrónica de Estudios Internacionales (REEI), nº 19, 2007.

De Miguel Bárcena, Josu. “La justicia constitucional en la teoría de la Constitución Europea”, En:G Bazán, Víctor (Coordinador), Derecho Procesal Constitucional Americano y Europeo, Buenos Aires, Abeledo Perrot, 2010.

De Vergottini, Giuseppe. Garantía “de la identidad de los ordenamientos estatales y límites de la globalización”, en: Teoría y Realidad Constitucional, n ${ }^{\circ}$ 18, Madrid, España, UNED, 2006.

Dieter-Borchardt, Klaus. El ABC del Derecho Comunitario. Bruselas, Bélgica: Documentación Europea, 2000.

Eleftheriadis, Pavlos. "Parliamentary Sovereignty and the Constitution", en: Canadian Journal of Law and Jurisprudence, vol. XXII, n² ${ }^{\circ}$, Ontario, Canadá, 2009.

Garot, Marie-José. "La Constitución francesa y el derecho comunitario: un repaso de la historia entre dos ordenamientos jurídicos", en: Revista Cuadernos de Derecho Público, Instituto Nacional de Derecho Público, Madrid, España, 2008.

Häberle, Peter. "El Estado Constitucional europeo", en: Revista de Derecho Constitucional Europeo (ReDCE), ${ }^{\circ} 11$, Granada, España, 2009.

“La constitución en el contexto", en: Anuario Iberoamericano de Derecho Constitucional, n * 7, Granada, España, 2003.

Hesse, Konrad. "Constitución y Derecho Constitucional” En: Manual de Derecho Constitucional, Instituto Vasco de Administración Pública, Madrid, España, Marcial Pons, 1996.

IzA, Alejandro. Unión Europea ¿Paradigma de la integración?, Buenos Aires, Departamento de Publicaciones, Facultad de Derecho, UBA, 2004.

Lindfelt, Mats. A bill of rights for the European Union?. Institute for Human Rights, Åbo Akademi University, 1999.

Ortiz Vaamonde. Santiago, "El Tribunal Constitucional ante el derecho comunitario”, en: Revista Española de Derecho Constitucional, Año 21, n ${ }^{\circ}$ 61, Madrid, Espańa, 2001. 
DERECHO Y HUMANIDADES, $\mathrm{N}^{\circ}$ 19, 2012, pp. 297-316

Leandro Ferreyra / Limites constitucionales del principio de primacía del derecho comunitario

Rodríguez Iglesias, Gil Carlos. "El Consejo Constitucional de Francia reconoce la competencia exclusiva del juez comunitario para examinar la validez de una directiva”, en: Revista Derecho Comunitario Europeo, n ${ }^{\circ} 18$, Madrid, España, 2004.

ScotTI, Luciana. "La integración regional y el Derecho de la Integración - El caso del MERCOSUR: luces y sombras", en: Suplemento mensual de Derecho Internacional Privado y de la Integración, ${ }^{\circ}$ 18, Buenos Aires, Diario Jurídico El Dial, 2006.

Teruel Lozano, Germán M. "El Tribunal Constitucional ante el principio de primacía en el derecho comunitario", en Anales de Derecho, n ${ }^{\circ}$ 26, Murcia, España: Universidad de Murcia, 2006. 